\title{
0 milagre irlandês como exemplo da adoção de uma estratégia nacional de desenvolvimento
}

\author{
ALEXANDRA STROMMER DE FARIASGODOI*
}

\section{The Irish miracle as an example of the adoption of a national development stra-} tegy. This paper discusses the Irish experience in the $90 \mathrm{~s}$, and details the main aspects of the impressive and rapid transition from a situation of excessive indebtedness, economic stagnation and high unemployment to sustainable growth. The presence of a national development strategy seems to be the crucial institutional tool that allowed this transition.

Key-words: Ireland, development strategy, public policies, social pact.

JEL Classification: 043.

A notável performance da economia irlandesa nos últimos 25 anos é tema fundamental aos interessados no processo de desenvolvimento econômico. Em um período histórico relativamente curto, o PIB per capita subiu de $€ 3.684 \mathrm{em}$ 1980 para $€ 32.127$ em 2005 , o terceiro maior do mundo ajustado por paridade de poder de compra, enquanto a taxa de desemprego caiu de um patamar próximo a $18 \%$ em meados da década de 1980 para 4,2\% em 2005. 0 crescimento médio anual do PIB, de $2,0 \%$ a.a. no período $1980-85$, atingiu $6,9 \%$ na década de 90 e continua elevado, em $6,2 \%$, entre 2000 e $2005 .{ }^{1}$

A experiência irlandesa apresenta características particulares que podem ser de bastante interesse ao caso brasileiro, particularmente o fato de ter superado as armadilhas advindas da seguinte situação histórica:

- Grave crise após os choques do petróleo na década de 1970 e a elevação das taxas de juro internacionais na década de 80 , que levou a uma situação crônica de alta inflação.

\footnotetext{
* Escola de Administração de Empresas de São Paulo, da Fundação G etúlio Vargas. E-mail: alegodoi@terra.com.br. Submetido: Janeiro, 2005; aceito: Setembro, 2006.
}

${ }^{1}$ D epartment of Finance (2006). 
- Programa de estabilização na década de 1980, baseado na utilização de uma âncora cambial (no caso, o ECU), bem-sucedido no controle da inflação, mas que resultou no alto endividamento do país e na vulnerabilidade a choques externos.

- Seguidas tentativas frustradas de controlar o problema do alto endividamento, cujas conseqüências eram uma elevadíssima carga tributária, baixo investimento e, conseqüentemente, a semi-estagnação da economia com altas taxas de desemprego.

A pesar dos prognósticos pessimistas, a Irlanda conseguiu ao longo da década de 1990 escapar da armadilha do baixo crescimento pós-estabilização. Além disso, em um período bastante curto em termos históricos o país foi bem-sucedido em absorver grande parte da mão-de-obra que era ocupada pelo setor tradicional em indústrias modernas e serviços. Em 1979 praticamente $20 \%$ da força de trabalho se concentrava na agricultura, número que caiu para apenas $6 \%$ em $2005,{ }^{2}$ e isto foi feito de forma relativamente pouco traumática em termos sociais. Por fim, a Irlanda teve que superar a crônica falta de confiança em suas instituições, o que dificultava a implementação de planos de ajuste e reformas. $M$ ais ainda, este processo de mudança institucional e desenvolvimento ocorreu em um ambiente extremamente democrático, ao contrário do que sugerem algumas experiências asiáticas.

A ssim, acredito que algumas das lições da experiência irlandesa possam ser úteis na busca de políticas adequadas para o desenvolvimento brasileiro. A pesar desta mensagem estar implícita ao longo do trabalho, é preciso deixar claro que o presente artigo limita-se à análise da experiência irlandesa propriamente dita, sem a pretensão de oferecer um estudo comparativo ou de aplicabilidade das políticas discutidas ao caso brasileiro.

Grande parte dos estudos na literatura procura explicar o sucesso irlandês nomeando um cardápio de políticas que teriam sido acertadamente praticadas pelo poder público do país e que, combinadas com condições culturais, sociais e geográficas pré-existentes, explicariam o boom de desenvolvimento presenciado na década de 1990. O presente artigo procura tratar a questão sob uma outra perspectiva, com foco nas motivações e encadeamentos que teriam possibilitado a escolha e a implantação destas mesmas políticas. Desta forma, procura-se analisar os fatos históricos que, em um certo momento do tempo, afetaram a dinâmica institucional do país, permitindo à Irlanda selecionar políticas apropriadas e beneficiar-se destas condições particulares de sua sociedade e geografia, presentes anteriormente, porém sub-aproveitadas.

0 artigo argumentará que o excepcional desempenho da economia irlandesa resulta da implementação eficaz de uma estratégia nacional de desenvolvimento, conforme entendida por Bresser-Pereira (2005), segundo a qual os diversos

${ }^{2}$ D epartment of Finance (2006). 
grupos sociais (políticos, burocratas do estado, empresários e trabal hadores) são capazes de agir de forma coordenada, apesar dos conflitos internos inerentes, frente ao desafio de competir em uma economia globalizada. M ais do que a adoção de políticas específicas, liberais ou intervencionistas, uma estratégia nacional consiste na construção de uma "instituição através da qual a nação orienta a ação dos agentes econômicos nacionais e reduz sua incerteza" (Bresser-Pereira 2005, p. 3); em um processo de planejamento estratégico em que se estabelece o objetivo a ser atingido pela nação, no caso, o desenvolvimento econômico, e a partir daí adotam-se de forma pragmática ações e políticas adequadas às características históricas da economia em questão.

A ceitando-se esse pressuposto, dissolve-se um dilema ideológico que permeia muitas análises da experiência irlandesa, já que a mesma não pode ser classificada muito propriamente como exemplo da adoção de um modelo ortodoxo eliberal, nem estritamente como uma experiência heterodoxa e intervencionista. $\mathrm{N} \mathrm{a}$ verdade, deve-se admitir que a experiência irlandesa combina a adoção de medidas da agenda ortodoxa, tais como o foco na disciplina fiscal com redução de impostos e abertura da economia para o comércio e para os fluxos de investimento direto e de mão-de-obra, com elementos mais heterodoxos como a implementação de políticas industriais ativas e a adoção de pactos sociais coordenados pelo governo. Como coloca a revista Economist (15/05/97), "statists note with satisfaction high rates of personal taxation, generous welfare payments, and ambitious industrial strategy. Liberals see an economy exceptionally open to trade and investment, favourable demographics, negligible public borrowing and a labour market that is oddly flexible".

0 artigo está assim estruturado: a primeira seção descreve brevemente as principais características da economia irlandesa, fornecendo o arcabouço para a compreensão do contexto histórico que permitiu o surgimento do consenso em torno de uma estratégia nacional de desenvolvimento. A seguir descreve-se a forma fundamental de implementação desta mesma estratégia, a saber, os pactos sociais. Posteriormente, trataremos do processo de fortalecimento institucional e do Estado, que aparece simultaneamente como pré-condição e conseqüência da adoção de uma estratégia deste tipo. Por fim, apresentaremos alguns resultados do processo e nossas conclusões.

\section{O CONTEXTO HISTÓRICO: CARACTERÍSTICAS GERAIS DA IRLANDA}

A Irlanda, com uma população de aproximadamente 4 milhões de pessoas em 2005, caracteriza-se como uma pequena economia aberta dependente do comércio internacional, cujo produto representa cerca de $2 \%$ do produto total da área do euro. Esta abertura reflete-se na alta participação de bens importados e exportados no PIB, de quase $155 \%$ em 2005, uma das mais altas do mundo, bem como na considerável mobilidade internacional de sua mão-de-obra, através de 
fortes fluxos migratórios, e de seu capital, expressa nos altos níveis de investimento direto estrangeiro. ${ }^{3}$

$\mathrm{N}$ as últimas duas décadas a economia irlandesa transformou-se de uma base agrária e de manufatura tradicional para uma economia crescente e baseada nos setores de alta tecnologia e de serviços internacionais. Em 2005, o setor de serviços representou $66 \%$ do emprego total, a indústria, $28 \%$, e a agricultura, somente $6 \%$. Ao longo deste perío do (1987-2005), registrou-se um crescimento econômico sem precedentes que permitiu que o PIB real irlandês mais que triplicasse em tamanho, atingindo $€ 161$ bilhões em 2005, e levou a uma rápida convergência do PIB per capita à média da comunidade européia e a um crescimento extraordinário no emprego. A taxa de desemprego, como conseqüência, caiu de quase $18 \%$ no início da década de 1980 para recordes historicamente baixos em torno de $4 \%$ nos anos recentes. ${ }^{4}$

\section{Crescimento do PIB}

(em \%)

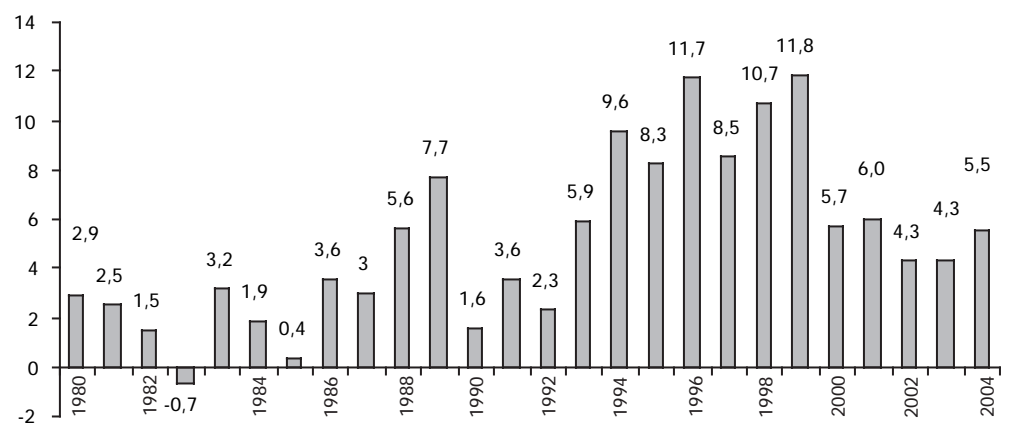

Força de Trabalho no Setor Agrícola

(em \% de empregados)

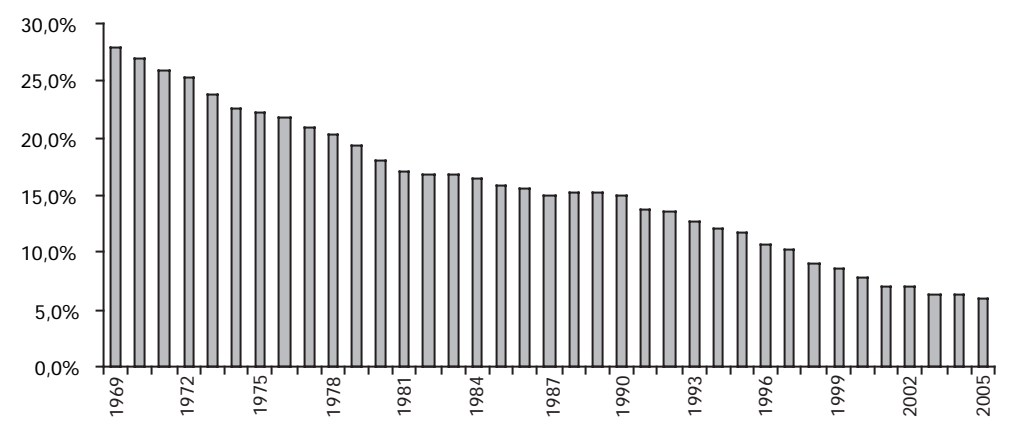

${ }^{3}$ D epartment of Finance (2006)

${ }^{4}$ D epartment of Finance (2006) 
Taxa de Desemprego

(em \%)

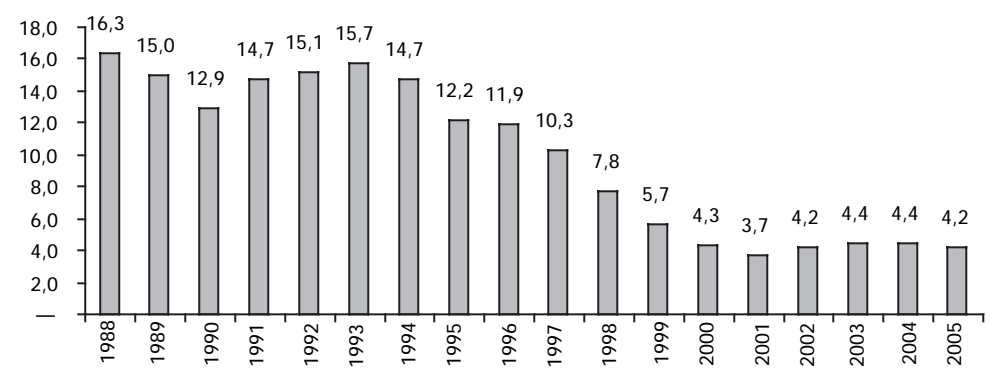

Fonte: Departament of Finance (2006)

Como colocam M cCarthy (2001), O 'G rada (2001) e Lee (1989), no início do século os padrões de vida na Irlanda eram comparáveis àqueles das economias do norte europeu, como a N oruega e a Finlândia, com renda per capita de aproximadamente $50 \%$ da Inglaterra, mas superior a países como a Itália, Grécia e Portugal, e estava convergindo aos níveis da Inglaterra e da maior parte da Europa 0 cidental. Entretanto, a partir da independência em 1920 a posição relativa da Irlanda começou a se deteriorar. As explicações oferecidas para esta fraca performance econômica incluem restrições institucionais e culturais à performance bem como políticas de industrialização com substituição de importação de pouco sucesso tentadas a partir de 1932 . Em 1960 a população do país tinha se reduzido para 2,8 milhões de pessoas, a mais baixa em dois séculos e muito inferior aos 8 milhões em 1840 que faziam da Irlanda um dos países mais densamente povoados da Europa na época.

Os dois choques do petróleo na década de 1970, combinados com os efeitos, no início dos anos 80, das altas taxas de juro internacionais resultantes das políticas anti-inflacionárias da era Volker, levaram a uma crise fiscal e externa de graves proporções. A Irlanda era muito dependente da importação de petróleo, e por isso sofreu choques externos fortíssimos em 1974/75 e depois novamente em $1980 / 81$ de $7 \%$ a $10 \%$ do PIB em cada um desses anos. A proximadamente $60 \%$ do ef eito dos choques ocorreu devido à deterioração dos termos de troca, e $25 \%$, ao desaquecimento da economia global (O 'G rada e O 'R ourke, 1995). A resposta ao primeiro choque foi tomar empréstimos externos e adotar uma política fiscal anticíclica de forma a amenizar os efeitos recessivos. Entretanto, mesmo quando a posição de termos de troca continuou desfavorável ao longo da maior parte da década de 1970, as autoridades decidiram continuar a proteger o nível de emprego utilizando recursos externos. Isto levou a uma maior vulnerabilidade da economia quando da ocorrência do segundo choque do petróleo. A situação se complicou ainda mais com a elevação das taxas de juro internacionais, o que levou a uma dívida externa explosiva. Como conseqüência, durante grande parte do século XX até o final da década de 1980, os resultados econômicos da Irlanda fo- 
ram bastante fracos, combinando estagnação, taxas de inflação relativamente altas e crise fiscal. A situação aparentemente crônica de desemprego levou a um grande fluxo de emigrantes e prejudicou a atividade empresarial.

No final de 1981 a taxa de inflação ao consumidor atingiu um pico de $25 \%$ a.a., e o sentimento de instabilidade atingiu seu auge conforme o diferencial de taxas de juro em relação aos países desenvolvidos da Europa se alargava rapidamente. Em 1982, uma mudança de governo criou o momentum para um processo de ajuste cuja necessidade já havia se tornado um consenso na sociedade. As principais medidas adotadas (D ornbusch, 1988) foram:

- Fixação do câmbio, no contexto da âncora fornecida pelo EM S (sistema monetário europeu);

- Política fiscal austera, com redução do déficit primário de 7,2\% em 1979/81 para 1,9\% em 1983/84;

- Aplicação de taxas de juro reais positivas, após anos de taxas negativas;

- D esindexação e desacel eração das taxas de reajuste salariais, em função do crescente desemprego e de acordos salariais negociados.

0 esforço de estabilização foi reforçado por uma política monetária restritiva, com taxas de juro internas bastante superiores às internacionais, e por uma política cambial rígida. N o período de 1982-88 a inflação caiu para níveis em torno de $2 \%$, o país conseguiu produzir um superávit primário, mas a economia apresentava-se extremamente deprimida. A pesar da emigração, os níveis de desemprego estavam elevados - aproximadamente 18\% em 1987 - enquanto a dívida pública atingia $118 \%$ do PIB. H avia inclusive discussões sobre um possível default (M CC arthy, 2001). Para piorar a situação, em 1986-87 observou-se uma forte desval orização da libra esterlina, o que deteriorou significativamente a posição competitiva da Irlanda junto ao R eino Unido, seu principal parceiro comercial, origem de $40 \%$ das importações irlandesas e destino de $30 \%$ de suas exportações.

Em agosto de 1986, por ocasião do realinhamento do EM S, a Irlanda decidiu desvalorizar sua moeda em $8 \%$, o que foi insuficiente para eliminar especulações sobre uma nova desvalorização. 0 diferencial de juro com relação ao marco alemão subiu de $3 \%$ para $8 \%$, refletindo a vulnerabilidade do país a choques externos. 0 governo combateu a deterioração das expectativas e a conseqüente fuga de capitais com uma política monetária ainda mais restritiva, elevando as taxas básicas de juro de $10 \%$ para $14,6 \%$, bastante altas considerando-se que a inflação anteriormente se encontrava em níveis próximos a 2\% . Em 1988, um maior aperto fiscal, altas taxas de juro e, conseqüentemente, alto desemprego, trouxeram as taxas de inflação de volta aos níveis anteriores (D ornbusch, 1988; M cAleese e M cC arthy, 1989).

A pesar da manutenção da estabilidade, a crise teve o importante efeito de mobilizar a sociedade e exigir das classes políticas uma movimentação no sentido de tirar o país de uma situação crônica de baixas taxas de crescimento e alto 
desemprego. Como coloca M cCarthy (2001), um consenso amplo emergiu entre os principais agentes de que a situação teria que ser tratada e que, em particular, as finanças públicas teriam que ser equacionadas. Em 1987, o recém eleito primeiro-ministro C. H aughey (partido Fianna Fail) conseguiu aprovar uma série de reformas, com apoio da oposição, com o objetivo de equacionar a situação fiscal e reverter a situação crônica de desemprego, forte emigração, baixo crescimento econômico e deterioração geral dos padrões de vida.

\section{ELEM ENTOS DA ESTRATÉGIA N ACION AL DE DESEN VO LVIM ENTO}

M uitas razões têm sido apresentadas para explicar a rápida transição da Irlanda da situação crítica descrita acima para um cenário de taxas de crescimento excepcionalmente altas, das quais as mais comumente mencionadas são: a adesão à União Européia e o acesso ao M ercado Comum, baixas alíquotas de imposto corporativo, grande capacidade de atração de investimento direto estrangeiro, mão de obra abundante e qualificada após substanciais investimentos em educação e treinamento, acordos de parceria social coordenados e uma posição financeira do setor público mais estável. M cC arthy (2001), por exemplo, oferece um eficiente diagnóstico nesta linha.

Existe, entretanto, um outro processo - institucional e estrutural - que antecede a aplicação de políticas específicas, a qual chamaremos da adoção de uma estratégia nacional, e que consiste na formação de um consenso social em torno da busca do desenvolvimento econômico e, em linhas gerais, da tática a ser empregada. Este consenso facilita a negociação entre as classes e explicita os tradeoffs envolvidos, enfatizando e valorizando os benefícios comuns a serem obtidos pela $\mathrm{N}$ ação como um todo através de uma inserção bem-sucedida no cenário competitivo global. Uma percepção mais aguçada da existência de interesses nacionais comuns relacionados ao desenvolvimento econômico, que superam divergências e conflitos individuais e classistas, nos permite compreender parcialmente por que foi possível realizar em determinado momento ajustes que haviam fracassado repetidamente no passado. Este é o caso, por exemplo, da redução dramática do endividamento público, atingida em apenas três anos (1987-90), após numerosas tentativas anteriores de ajuste.

A motivação para a construção de uma estratégia deste tipo advém, no caso irlandês, de duas forças: (1) a crescente indignação da sociedade com o status quo de estagnação da economia e alto desemprego, como exposto na seção anterior, e (2) a adesão ao M ercado Comum Europeu, que tornou mais transparente a necessidade de coordenar esforços nacionais no sentido de competir internacionalmente e adicionou importantes el ementos motivacionais e institucionais. A forma pela qual a estratégia nacional foi implementada foi a adoção de pactos sociais amplos, como analisaremos a seguir. 


\section{A ESTRATÉGIA NACIONAL DE DESEN VOLVIMENTO NA FORMA DE PACTO SOCIAL}

0 primeiro passo da reforma iniciada em 1987 na Irlanda foi um pacto social, denominado Program for $\mathrm{N}$ ational R ecovery, ou PN R, que essencialmente consolidou um consenso em torno das medidas necessárias para a estabilidade e crescimento do país no longo prazo, e removeu boa parte do rancor do debate político e entre classes. 0 sucesso desta iniciativa levou à subseqüente edição de quatro pactos desde então, cada um com vigência de três anos, focando em questões específicas e definindo metas claras, baseadas no diagnóstico dos assuntos mais urgentes e importantes num dado momento do tempo. O s pactos aparecem como a expressão formal da estratégia nacional de desenvolvimento irlandesa, definindo prioridades e abrindo espaço para que conflitos entre classes sejam equacionados da melhor forma possível tendo em vista o objetivo comum do desenvolvimento econômico. Como coloca O 'D onnel (1998), os pactos representam "a shared understanding of the problems facing the Irish economy and society and the main lines of policy required to address them". D esta forma, eles encaixam-se perfeitamente à definição de estratégia nacional de desenvolvimento como "instituição que estabelece pautas para a ação econômica competitiva de empresários, de trabalhadores, das classes médias profissionais, e, dentro desta, da própria burocracia do estado" (Bresser-Pereira, 2005, p. 3).

A base para o estabelecimento das metas e iniciativas do PN R foi uma análise sobre estratégia de desenvolvimento produzida pelo $\mathrm{N}$ ational Economic and Social Council (N ESC) em 1986, um grupo criado com o objetivo de aconselhar o governo em assuntos relacionados ao desenvolvimento econômico e à busca de justiça social. Desde então, o N ESC tem funcionado como facilitador de consultas ao longo de diversas classes sociais, analisando assuntos de política e buscando consenso sobre medidas a serem adotadas. Com sede no gabinete do primeiro ministro, o NESC tem como membros representantes do governo, dos sindicatos, das empresas e associações de empregadores, das associações agrícolas e, desde 1996, também de associações voluntárias e comunitárias. O s acordos negociados neste fórum são publicados na forma de um relatório detal hado, que conta inclusive com recomendações de política macroeconômica e reformas. 0 fato destes acordos serem o resultado de um processo consultivo intenso, envolvendo longas deliberações, negociações e barganhas sobre um conjunto de prioridades macro sócio-econômicas entre um grupo diverso de cidadãos representativos e membros do governo é certamente um caso interessante de participação popular na definição de políticas, e seu modelo operacional encaixa-se bastante bem na visão de Bresser-Pereira (2005, p. 2), segundo a qual a estratégia nacional tem "os empresários como agentes principais, a acumulação de capital e a incorporação de conhecimento à produção como forma prática de realização, e o governo como responsável pela intermediação dos interesses e pela definição das políticas adotadas como base em um acordo do qual façam parte os principais grupos sociais do país comprometidos com o desenvolvimento". 
No sistema irlandês, o governo ef etivamente serve como fórum dentro do qual o processo de busca de consenso opera. Ele envia convites aos participantes, determina os limites dentro dos quais a estrutura de parceria deve operar, modera demandas conflitantes efacilita o processo de negociação (Wagle e Shah, 2003). 0 processo é assim bastante diferente de uma interação bilateral tradicional. D entro do pacto, os trade-offs de uma decisão são apresentados mais claramente, e cada agente tem que explicar e assumir a responsabilidade por suas decisões frente aos outros.

Os acordos mais antigos, especialmente o primeiro (1987-90) tinham um foco macroeconômico mais estreito, e tratavam basicamente da negociação de salários nos setores público e privado por um perío do de três anos, com o objetivo central de manter disciplina fiscal e garantir a competitividade da economia. Conforme a estabilidade foi sendo alcançada, atenção crescente passou a ser devotada aos assuntos mais amplos de reforma estrutural e distributiva. $\mathrm{N}$ o começo dos anos 1990 o desemprego e a emigração eram as principais preocupações. Conforme os ganhos econômicos continuam ao longo da década, a ênfase passou crescentemente à coesão social, desenvolvimento regional e pobreza (Wagle e Shah, 2003).

A resolução da grave crise fiscal foi provavelmente a maior conquista do primeiro pacto social (H onohan, 1998). A lém disso, o estabelecimento de uma fórmula para reajustes salariais no médio prazo assegurou relações de trabalho relativamente pacíficas ao longo do período, e maior previsibilidade na economia. Ao mesmo tempo em que não se podem subestimar as conquistas e méritos dos pactos sociais, especialmente do primeiro, é preciso admitir que seu timing foi particularmente feliz. Os principais partidos políticos estavam dispostos a apoiar as medidas necessárias, e o desaquecimento da economia nos anos 1980 e 0 alarmante desemprego facilitavam um acordo tripartite entre sindicados, empregadores e governo. A lém disso, a economia global estava entrando numa fase de otimismo. Iniciado o círculo virtuoso, a confiança geral na política começou a crescer e a metodologia do acordo tripartite foi perpetuada.

Em grande parte das análises sobre o rápido progresso da Irlanda, o acordo entre classes tem sido identificado como força propulsora da mudança. Como sugere o relatório da OECD (2001), estabelecendo uma estrutura institucional e um processo pelo qual o governo, o setor privado e a sociedade civil tomam as principais decisões sócio-econômicas com apoio popular amplo, conseguiu-se criar um círculo de benefícios para todos os participantes através do restabelecimento da competitividade, e da manutenção de um clima de cooperação entre empregadores e empregados, o que por sua vez levou a um ambiente propício ao investimento e ao crescimento. A pesar dos argumentos de causalidade direta entre os pactos sociais e a virada dramática da economia irlandesa serem contestados por alguns, existe decididamente uma base para argumentar que a estabilidade trazida por estes compromissos multi-anuais de política e salários foi instrumental. A lém dos benefícios econômicos tangíveis, os pactos sociais, através de um processo de engajamento cívico, estimularam vários aspectos relacio- 
nados ao capital social. Por ser um processo que se repete a cada três anos, ele gera um ambiente de reciprocidade e confiança, em que a necessidade de se construir reputação estimula a cooperação, em contraposição à maximização de curto prazo do interesse individual.

A pesar dos resultados econômicos espetaculares obtidos através dos pactos sociais, muita discussão existe, ainda, sobre suas implicações mais amplas, já que eles representam uma inovação importante no espectro político (Wagle e Shah, 2003). Vários economistas neoclássicos argumentam, por exemplo, que os agentes deveriam agir segundo o interesse próprio, e que a colusão entre interesses em nome da parceria é uma distorção que criaria custos de peso morto. Por outro lado, deve-se considerar que o estabelecimento dos parâmetros de longo prazo, especialmente da taxa de câmbio, dá credibilidade ao regime de política do país, e as expectativas de inflação são minimizadas em função de compromissos críveis. Como conseqüência, explica O 'D onnell (1998), esses acordos tiraram a taxa de câmbio e a inflação do dia-a-dia político e empresarial.

0 utras críticas sugerem que tais acordos enfraqueceriam o processo democrático, influenciando as ações de um governo eleito através de canais extraconstitucionais. Entretanto, como colocam Wagle e Shah (2003), como o governo é ainda a força propulsora do processo, em algumas circunstâncias ele pode se afastar dos termos do acordo. Além disso, não há indicação de que o nível de competição política e accountabillity tenham caído em função dos pactos, apesar de todos os quatro principais partidos no parlamento terem participado do governo e operado os acordos com entusiasmo em algum momento.

Preocupações foram levantadas também com relação aos limites de exclusão e representação. Enquanto as parcerias sociais são estendidas para incluir organizações comunitárias e voluntárias, agentes dentro de cada setor divergem sobre quem os representa nas negociações e como. 0 equacionamento destes conflitos é um processo complicado, porém essencial para que todos os setores da sociedade sejam representados de forma legítimas nas negociações. Além disso, é fundamental que não haja complacência por parte do governo, que deve exercer uma forte liderança no processo e garantir que o trade-off entre interesses e agendas não seja viesado, e que o processo não fira princípios democráticos. Isto exige um Estado muito forte e capaz, além de incrivelmente autônomo e isento, como será discutido na seção seguinte.

$\mathrm{N}$ ão obstante, o próprio fato de um projeto que começou com uma solução de curto prazo para combater uma crise das finanças públicas ter sido institucionalizado e amplificado, de forma a "deliberar, negociar, barganhar e atingir consenso" (Wagle e Shah, 2003, p. 5) sobre questões econômicas e sociais de um país é uma indicação de que o modelo tem sido considerado bem-sucedido pelos próprios irlandeses. Para observadores externos, este exercício parece sugerir um caso de resultados econômicos impressionantes conseguidos através de um modelo inovador de governança negociado. 
Para que o sistema de pactos sociais pudesse funcionar de forma eficiente e justa, era necessário que o Estado estivesse capacitado a exercer sua importante função de líder, mediador e executor do processo. Isto demandava o fortal ecimento das instituições em geral, e do aparel ho do Estado em particular. É interessante ressaltar, entretanto, que este fortalecimento ocorreu apesar de uma redução do tamanho do Estado. $\mathrm{N}$ a verdade, o saneamento do setor público e a redução de seu endividamento, bem como o aumento de sua eficiência, parecem ter sido elementos essenciais ao processo de desenvolvimento, garantindo não só a estabilidade macroeconômica, mas também conferindo credibilidade às instituições e reduzindo o grau de incerteza da economia.

Desta forma, a primeira - e talvez a mais surpreendente - conquista da Irlanda através da adoção dos pactos sociais foi justamente o equacionamento do déficit público, que havia atingido proporções assustadoras no final da década de 1980, num prazo surpreendentemente curto de apenas três anos. A pesar de 0 ajuste ter ocorrido quase que integralmente do lado da despesa (em geral, a receita total do governo como fração do PIB era mais baixa em 1990 do que em 1986), o Estado irlandês foi capaz de manter, e talvez aumentar, sua capacidade de ação.

O s gastos correntes do governo caíram de 55\% do PIB em 1986 para 35\% em 2000 , subindo novamente para $40 \%$ em 2005 . A o mesmo tempo, a carga tributária caiu paulatinamente de um pico de 40\% do PIB em 1988 para 34\% em 2005. Em 1986 o déficit orçamentário corrente era de 7,9\% do PIB enquanto as necessidades de financiamento do governo eram de 14,2\% do PIB. Em 1990 estes números haviam caído para $0,6 \%$ e $2,8 \%$, respectivamente. Durante estes anos as receitas totais caíram de $37,9 \%$ para $34,5 \%$ do PIB enquanto as despesas caíram dramaticamente de $45,8 \%$ para $34,1 \% .{ }^{5}$ Dado o rápido crescimento do PIB neste período, as receitas não variaram muito em termos absolutos, mas os cortes de despesa foram substanciais. 0 endividamento público passou de $118 \%$ do PIB em 1987 para 28\% em 2005. ${ }^{6}$

\footnotetext{
${ }^{5} \mathrm{M} \mathrm{CC}$ arthy (2001, p. 14).

${ }^{6}$ Department of Finance (2006).
} 
Receita Tributária

(em \% do PIB)

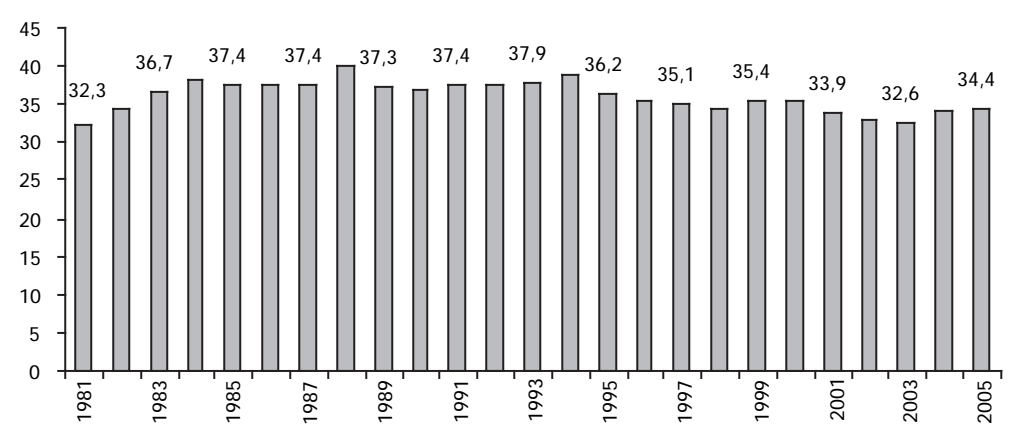

Gasto Público Total

(em \% do PIB)

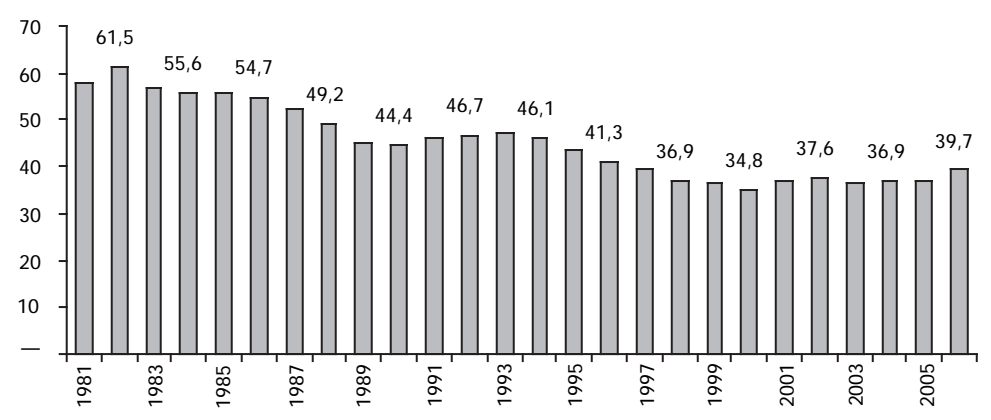

Fonte: Department of Finance (2006)

O s cortes em despesas foram amplos, mas os mais significativos foram reduções em transferências e em gastos com salários e investimentos. As políticas fiscais incluíram um congelamento no recrutamento em 1987 e um esquema de aposentadoria voluntária, que levaram a uma redução de $10 \%$ no número de funcionários públicos (de 300 para 270 mil) entre 1986-89. Como coloca M cC arthy (2001), todos os pleitos salariais por parte de funcionários públicos foram essencialmente recusados, e resistiu-se às demandas de grupos políticos locais. 0 pacto social com os sindicatos em 1987 garantiu um limite de 2,5\% para 0 aumento de salários, bem abaixo da inflação vigente. H ouve também cortes e adiamentos em programas de infra-estrutura pública.

Em 1989 introduziu-se uma ampla reforma tributária, cuja principal medida foi reduzir as alíquotas marginais do imposto de renda pessoa física e aumentar o valor das faixas de corte, o que beneficiou as camadas de mais baixa renda. A alíquota do imposto de renda pessoa jurídica também foi reduzida de $47 \%$ para $43 \%$. A tualmente a Irlanda oferece uma das mais baixas alíquotas de imposto de renda do mundo para empresas de manufatura e de serviços internacionais, 
apenas 10\%, para empresas nacionais ou estrangeiras. M esmo assim, a receita coletada pelo país é comparável com a de outros países com alíquotas duas ou três vezes maiores, dada a alta lucratividade da economia.

Além do corte de despesas, o governo também se beneficiou de uma anistia tributária em 1988, que trouxe resultados acima das expectativas. Esta anistia foi complementada por ameaças críveis de punição de crimes futuros, de forma que não apenas a receita imediata melhorou, mas a sonegação nos anos futuros foi reduzida. Por fim, as transferências de fundos estruturais por parte da Comunidade Européia al cançaram em média 4,1\% na década de 90,7 exercendo também ef eito bastante benéfico nas contas públicas. Estes recursos foram usados em grande parte para investimentos em infra-estrutura e para recomeçar os projetos deferidos durante a crise fiscal.

Como vimos, este fortíssimo ajuste só foi possível com o suporte claro de todos os principais partidos políticos e classes sociais. Como coloca M cC arthy (2001, p. 21), os objetivos foram apresentados claramente para o público por ocasião do primeiro pacto social, e exerceu-se forte liderança para alcançar os objetivos respaldados pela sociedade. 0 custo da estabilização foi comunicado de forma transparente e generalizada ao longo de todos os grupos, e garantiu-se que alguns direitosmínimos, basicamenteseguro-desemprego, educação esaúde, não seriam afetados pelos cortes. Para muitos analistas, a adoção do pacto social foi a peça-chave para quebrar o círculo vicioso em que o país se encontrava porque garantiu que todos os grupos importantes da sociedade estivessem conscientes dos objetivos e percebessem o que podiam ganhar com a adoção das medidas. A confiança que veio das medidas de estabilização críveis e do ajuste fiscal permitiu taxas de juro mais razoáveis o que, combinado com menores necessidades de financiamento e altas taxas de crescimento, levaram à gradual redução da dívida/PIB.

Dívida Pública

(em \% do PIB)

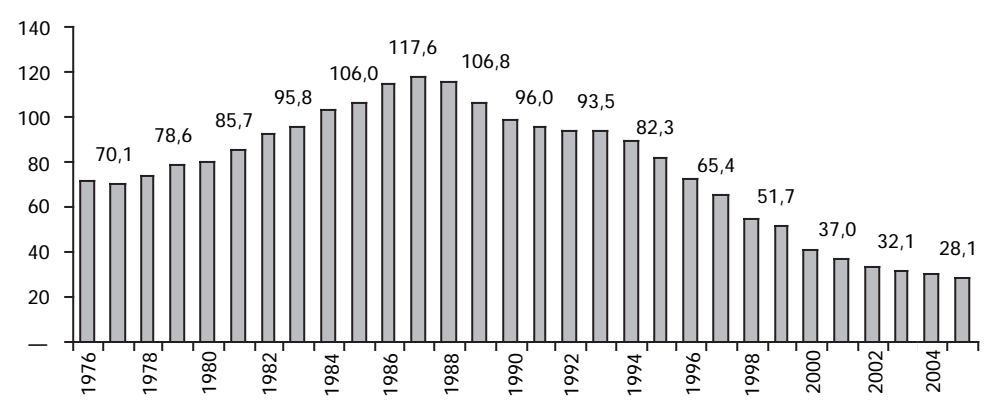

Fonte: Department of Finance (2006)

${ }^{7}$ D epartment of Finance (2006). 
0 intrigante da experiência irlandesa é compreender como foi possível que o processo de fortalecimento da atuação institucional do Estado se desse em um momento em que seus quadros e verbas eram reduzidos de forma significativa. A explicação para este aparente paradoxo não é simples. Em primeiro lugar, não se pode subestimar o elemento de credibilidade implícito no processo de ajuste do setor público. 0 Estado, dando à sociedade um exemplo claro de comprometimento com a estratégia nacional de desenvolvimento por meio da disposição de aceitar sacrifícios individuais (e.g., cortes drásticos de despesas e redução em seu quadro) em prol de um objetivo nacional mais amplo, confere enorme crédito aos pactos sociais e estimula a cooperação dos demais grupos.

A lém do elemento de credibilidade, entretanto, outros fatores contribuíram de forma significativa para esta evolução qualitativa das instituições estatais, dos quais mencionaremos dois: (1) a capacitação da burocracia estatal, que foi valorizada pelo novo modelo de governança, e (2) o ingresso na Comunidade Européia.

Como coloca M cC arthy (2001, p. 6), o serviço público foi, ironicamente, o grande beneficiado ao longo dos anos de estagnação e emigração nas décadas de 1970 e 1980, já que oferecia uma das principais possibilidades de emprego aos que escolhiam não emigrar. Isto, combinado a características culturais e educacionais favoráveis, bem como a uma herança inglesa de eficiência e baixa corrupção no serviço público, permitiu que a Irlanda desenvolvesse uma burocracia competente, autônoma e sintonizada com os interesses de outras classes. A entrada no serviço público se dava por um exame extremamente competitivo, e isto levou a uma burocracia estável e tecnicamente competente, que teve um papel importante na implementação das estratégias definidas pelo pacto social e na execução da política de incentivos que se seguiu. Valorizada pelo novo sistema de governança pautado nos pactos sociais, a burocracia estatal irlandesa pôde responder a contento e realizar um potencial latente que era anteriormente sobrepujado por uma estrutura de governo falida e paralisada.

A pesar da herança histórica favorável, o catalisador da reforma das instituições irlandesas foi, sem dúvida, seu ingresso na Comunidade Européia em 1973. Esta influência é bastante complexa, e inclui tanto efeitos diretos (como acesso a mercados, substancial transferência de recursos e melhoras de infra-estrutura) como, também, indiretos. Percebemos quatro canais principais através dos quais esta influência se manifestou de forma decisiva: cultura, incentivos e credibilidade, comércio e transferência de recursos.

Cultura: A implantação do M ercado Comum Europeu trouxe mudanças de comportamento e percepções, deixando mais explícita a necessidade do país tornar-se competitivo internacionalmente, ressaltando interesses nacionais comuns e promovendo a cooperação entre as diversas classes. Como coloca M cC arthy (2001, p. 7-8), anteriormente, o R eino Unido e os Estados U nidos tinham um papel dominante não só em termos econômicos e de comércio, mas também em como as pessoas formavam sua visão do mundo. A Irlanda teve uma longa tradição de emigração e trocas culturais com esses dois países, enquanto a política econômica era fortemente influenciada pelo R eino Unido, o parceiro comercial predominante. A crescente importância da dimensão européia levou ao despertar 
de uma natureza mais global e independente. A sociedade, antes profundamente patriarcal, se tornou mais cosmopolita, e o Estado, até recentemente muito influenciado pela Igreja Católica, foi se aproximando cada vez mais do modelo secular do restante da Europa.

Incentivos e credibilidade: Ao mesmo tempo, os fazedores de política conscientizavam-se das restrições impostas pelos acordos europeus e das recompensas que potencialmente adviriam da ação prudente. A estrutura institucional provida pelo arcabouço europeu ajudou a promover um comportamento mais transparente e responsável, suportado por melhor monitoramento e accountability, especialmente no uso de recursos públicos. Ela funcionou também como sancionador das políticas, dando-Ihes credibilidade e assegurando, de certa forma, seu caráter duradouro, o que teve efeitos extremamente positivos nas expectativas de investidores e empresários. Conforme este círculo virtuoso foi sendo despertado, houve um aumento persistente no espírito empresarial geral, com uma atitude mais positiva de que era possível fazer as coisas (M cCarthy, 2001).

Comércio: Sob o novo regime de livre comércio sem barreiras internas a partir de 1977, as exportações irlandesas cresceram rapidamente de $38 \%$ do PIB em 1973 para $86 \%$ em $1999 .{ }^{8}$ A o mesmo tempo, a composição do comércio mudou significativamente da exportação de bens primários agrícolas para manufaturas e, mais recentemente, serviços. A direção do comércio também se alterou, e a participação dominante do Reino Unido caiu de forma significativa de $34,2 \%$ em 1987 para 17,3\% em 2005. Curiosamente, a participação da União Européia caiu um pouco de 73,5\% em 1987 para 63,6\% em 2005, enquanto a participação do N AFTA cresceu substancialmente de 8,8\% em 1987 para 21,4\% em $2005^{9}$. Isto se deve à estratégia irlandesa de se posicionar como um veículo para que empresas americanas acessem o mercado europeu.

\section{Crescimento das Exportações \\ (em \%)}

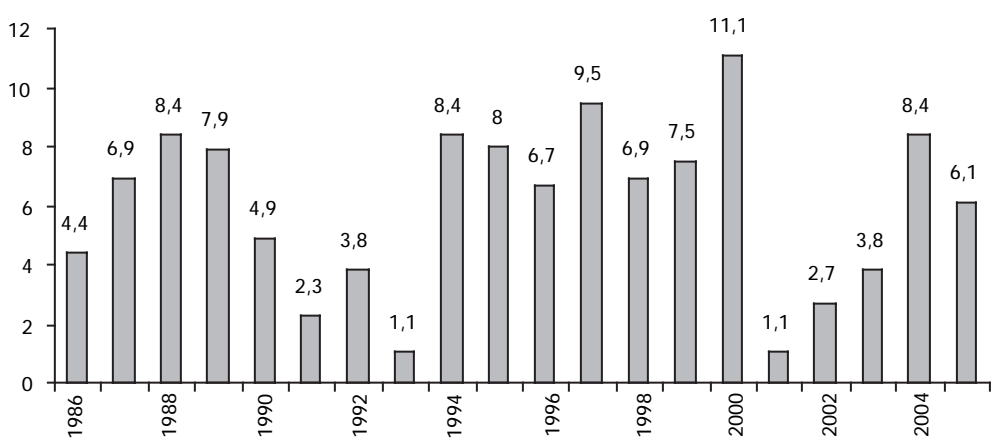

Fonte: Department of Finance (2006)

\footnotetext{
${ }^{8} \mathrm{M}$ CC arthy $(2001$, p. 8).

${ }^{9}$ Department of Finance (2006) e M cCarthy (2001).
} 
Transferência de recursos: A dicionalmente, a Irlanda se beneficiou significativamente de substanciais transferências de recursos da Comunidade Européia, que representaram, em termos líquidos, 3,4\% do PIB entre $1973-79,4,1 \%$ na década de $1980,4,3 \%$ na década de 90 , caindo para $1,1 \%$ entre $2000-05 .{ }^{10}$ Vale notar, entretanto, que outros países receberam transferências de recursos de magnitude similar, sem obter os mesmos resultados. A própria Irlanda vinha recebendo aportes significativos de recursos desde 1973, sem conseguir inicialmente resultados óbvios. A Comunidade Européia reconhece que a Irlanda da década de 90 é um exemplo notável de uso muito efetivo dos recursos recebidos, e mesmo assim os especialistas estimam que essas transferências tenham el evado a taxa anual de crescimento do país em apenas 0,5 p.p. ao longo da década de 90 (sobre um crescimento médio de $6,9 \%$ a.a.). Entretanto, tais transferências foram muito úteis durante o período de transição, criando proteções temporárias para os setores perdedores no processo de industrialização, diminuindo potenciais conflitos e neutralizando a oposição dos setores tradicionais à modernização da economia.

Um caso notável foi a agricultura. Estima-se que a Irlanda tenha se beneficiado de proteções e subsídios equivalentes a 2 a $6 \%$ do PIB a.a. através da Política Agrícola Comum (CAP) ${ }^{11}$. A pesar das crescentes discussões sobre os efeitos questionáveis no longo prazo de uma política agrícola protecionista, o fato é que os subsídios do CAP representaram um importante colchão, amenizando os efeitos de uma brutal transição de uma economia agrícola para uma industrial e de serviços. Em 1981, 17,1\% da força de trabalho empregada $(196,000$ trabal hadores) estava no setor agrícola, participação que caiu paulatinamente para 5,9\% $(114,000)$ em $2005^{12}$ conforme a economia foi se desenvolvendo. Como coloca M cCarthy (2001), o interessante da experiência irlandesa é que a forte queda no emprego no setor tradicional não foi acompanhada por grandes conflitos sociais como em outros países, já que muito do trabal ho excedente foi absorvido, inicialmente pela emigração, e, nos anos 90 , pelo forte crescimento irlandês em setores modernos, especialmente serviços, e de uma política ativa de combate ao desemprego.

A lém dos fundos do CAP, a I rlanda recebeu também recursos de outros fundos estruturais, direcionados primordialmente para o desenvolvimento de infraestrutura física e social. 0 gráfico abaixo consolida todas as transferências líquidas recebidas.

\footnotetext{
${ }^{10}$ Department of Finance (2006).

${ }^{11} \mathrm{M}$ cC arthy (2001, p. 9).

${ }^{12}$ Department of Finance (2006).
} 
Transferências Líquidas da Comunidade Européia

(em \% do PIB)

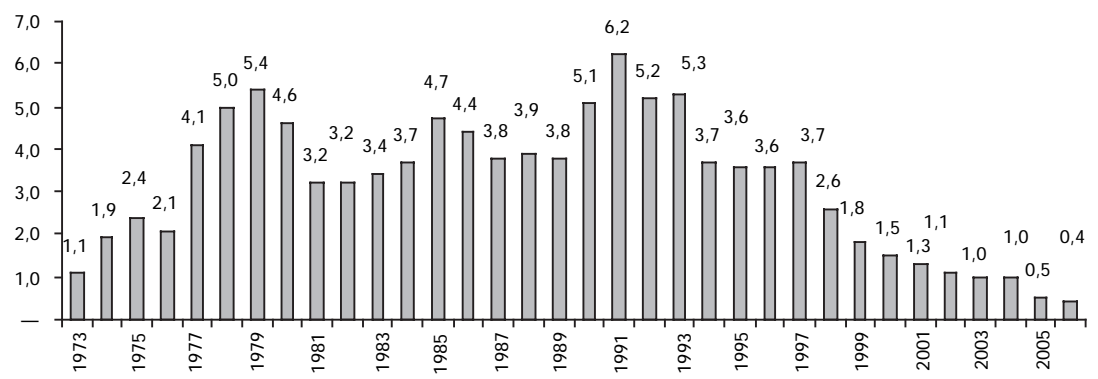

Fonte: Department of Finance (2006)

Além da viabilização dos pactos sociais, o Estado, fortalecido, foi capaz de executar com sucesso uma política industrial ambiciosa, investir fortemente em educação e criar uma rede de proteção social para amenizar os custos para os segmentos menos preparados da sociedade da transição de uma economia tradicional para uma economia moderna. M ais ainda, uma burocracia autônoma foi fundamental na resistência a pressões por parte de outros países da Comunidade Européia, como a Alemanha e a França, em pontos em que os interesses eram conflitantes, como a aplicação de alíquotas de imposto baixas para atrair investimentos externos. A nalisaremos a seguir brevemente alguns destes pontos.

\section{Política Industrial}

A lém das medidas de estabilização, a estratégica nacional de desenvolvimento irlandês previa a adoção de políticas ativas de estímulo direto ao crescimento e redução do desemprego. Dada a alta dívida externa e vulnerabilidade do Balanço de Pagamentos, bem como características estruturais particulares do país como, por exemplo, seu tamanho, optou-se por uma estratégia em que o setor exportador desempenharia o papel principal na recuperação da economia, o que requeria uma economia competitiva suportada por investimentos adequados. Entretanto, como coloca M cC arthy (2001, p. 11), a economia doméstica, após anos de fracos resultados, estava mal-preparada para enfrentar a competição internacional e o país enfrentava dificuldades estruturais em termos de comunicações, transporte e energia.

O governo irlandês decidiu assim desenvolver e implementar uma política industrial bastante focada, que objetivava atrair investidores estrangeiros, especialmente americanos, dos setores mais dinâmicos da economia mundial à época: tecnologia da informação, química e petroquímica. A execução da estratégia ficou a cargo da Autoridade de Desenvolvimento Industrial (IDA), órgão já existente e com alguma experiência passada em atrair firmas estrangeiras (apesar de com resultados ambíguos). I dentificaram-se as vantagens competitivas da Irlanda 
em relação a outros pólos de atração de investimento direto estrangeiro: capital humano (i.e. força de trabal ho altamente qualificada e que falava inglês), boas relações de trabalho em função dos pactos sociais, acesso ao mercado europeu e baixas alíquotas de impostos corporativos (10\% pós 1979), com acordos que evitam a bi-tributação com os EUA etc.

A IDA agiu eficientemente atraindo um número de empresas-bandeira, particularmente no setor de informática e eletrônicos, que apresentavam rápido crescimento global, como Intel, IBM , M otorola e M icrosoft. Cerca de um terço dos computadores pessoais vendidos hoje na Europa são fabricados na Irlanda, e o país recebeu $40 \%$ do todo investimento americano no setor de eletrônicos europeu desde 1980. Hoje a Irlanda é o maior exportador do mundo de software, na frente inclusive dos Estados Unidos. Ao mesmo tempo, a ID A ofereceu uma boa plataforma para muitas multinacionais nos setores químico e farmacêutico. M ais recentemente, setores de serviços, como de telemarketing, bem como bancos internacionais e outras instituições financeiras passaram a ser o foco da IDA. H oje, Dublin é a sede das operações de back-office e processamento de dados de mais de 400 bancos e corretoras que empregam 16.000 pessoas. A capacidade da Irlanda de estabelecer clusters de firmas relacionadas capazes de suprir umas às outras e criar um pool de trabalho qualificado é, certamente, um fator fundamental para o sucesso da política industrial irlandesa.

A Irlanda atrai hoje cerca de um quarto de todo investimento direto americano na Europa. Ela conta com mais de 1.100 empresas multinacionais que exportam cerca de US\$60 bilhões por ano. De acordo com a OECD, o estoque de investimento direto americano na Irlanda havia atingido US\$10 bilhões no final de 1994, ou US\$3 mil per capita, mesmo nível do Reino Unido e seis vezes superior à França ou A lemanha. Empresas estrangeiras na Irlanda detêm hoje cerca de $30 \%$ da economia e $40 \%$ das exportações. Seu produto por trabalhador é cerca de três vezes maior do que o das empresas nacionais.

Enquanto as empresas domésticas eram inevitavelmente mais lentas em reagir à melhora das condições macroeconômicas, estas multinacionais dinâmicas foram capazes de produzir um dramático crescimento nas exportações. Entre 1986-2005 as exportações mostraram um crescimento anual médio de 6,0\%. ${ }^{13}$ Durante o primeiro pacto trienal, o forte crescimento do PIB e especialmente das exportações não foi acompanhado por melhoras significativas do desemprego, 0 que gerou bastante discussão sobre o modelo, levantando questões como se as multinacionais produziriam apenas crescimento sem emprego, ou se elas estavam apenas transferindo produtos entre fronteiras a preços fictícios para se beneficiarem de alíquotas de imposto favoráveis (M cCarthy, 2001, p. 11). Porém, nos anos que se seguiram ficou evidente que estas novas companhias estavam construindo cadeias com supridores domésticos e estimulando o aproveitamento de habilidades empresariais locais. M uitas inclusive construíram operações bastante com-

${ }^{13}$ Department of Finance (2006). 
plexas e diversificadas na Irlanda, em algumas vezes seus próprios headquarters europeus, o que representou uma grande evolução comparado com outros momentos da história irlandesa.

Entretanto, não podemos negar que o sucesso da estratégia irlandesa se deveu em parte ao fator sorte. Dado o pequeno tamanho do mercado doméstico, 0 produto das empresas era altamente dependente da demanda externa, e, portanto, sensível à economia global. 0 período de excepcional desempenho do setor de tecnologia que se seguiu remunerou enormemente a estratégia adotada. Porém, como afirma $M$ cCarthy (2001, p. 12), os riscos de um desaquecimento da economia global, ou mesmo de um êxodo por parte das multinacionais em busca de condições mais vantajosas em outros países, ficam potencializados em função dos efeitos de encadeamento com as firmas domésticas. N este contexto, seria interessante examinar quanto do sucesso da iniciativa de atração de empresas estrangeiras se deve a fatores permanentes, como capital humano e acesso ao mercado europeu, e quanto se deve ao regime tributário favorável e outras medidas pontuais mais facilmente replicáveis.

\section{Educação e Programas Sociais}

Como vimos, um dos principais atrativos da Irlanda na década de 1990, e fator determinante do sucesso da política industrial implementada, foi a oferta abundante de trabalhadores qualificados, incluindo cientistas, engenheiros e administradores. Desde a década de 1960 o governo irlandês vem investindo fortemente na educação fundamental e superior, e, mais recentemente, as universidades principais vêm se especializando em oferecer recursos importantes para empresas nos setores de tecnologia da informação, farmacêutica e saúde. Além de uma política pública adequada nesta área, a Irlanda se beneficiou de fatores demográficos como uma população mais jovem em comparação com o restante da Europa e em crescimento. Ao mesmo tempo, fundações direcionadas para a pesquisa usam recursos públicos para atrair para a Irlanda cientistas e pesquisadores de ponta no mundo, muitos dos quais de origem irlandesa, e trabal ham em forte parceria com as universidades.

Paralelamente às políticas na área de educação, desenvolveu-se uma política de emprego ativa com verba de cerca de $1,75 \%$ do PIB, ${ }^{14}$ envolvendo, por exemplo, um esforço de treinamento pelo setor público dos desempregados crônicos (há mais de 12 meses), que não tinham capacitação para serem absorvidos pelo setor moderno da economia. A lém disso, as redes de proteção social foram mantidas para aparar segmentos da sociedade menos capacitados para participarem desta transição, o que garantiu que importantes benefícios sociais como segurodesemprego e aposentadorias fossem mantidos, em termos reais, mesmo durante o perío do de forte ajuste fiscal (O 'Connel e R ottman, 1992).

${ }^{14}$ M cCarthy (2001, p. 19). 
Este artigo procurou demonstrar que, mais do que um cardápio de políticas específicas, a experiência irlandesa traz como lição a idéia de que o desenvolvimento econômico depende da adoção de uma estratégia nacional, ou seja, da constituição de um consenso entre os diversos segmentos da sociedade sobre a necessidade de reformas que busquem o crescimento e 0 aumento do emprego. No caso irlandês, a existência deste consenso levou à cooperação em torno do mecanismo de pactos sociais, que permitiram o ajuste das contas públicas, trouxeram estabilidade às relações de trabalho, definiram prioridades, reduziram a incerteza e personificaram a existência de uma estratégia nacional de desenvolvimento.

Simultaneamente verificou-se um processo de fortalecimento das instituições e do aparelho do Estado, capacitando-o para liderar e executar de forma eficiente (1) as estratégias definidas pelos diversos pactos sociais (inclusive, inicialmente, o próprio ajuste fiscal do Estado), (2) uma política industrial ativa e focada e (3) políticas assistenciais que amenizassem os efeitos da transição em grupos menos preparados. Este fortalecimento institucional ocorreu apesar de uma redução no tamanho do Estado - na verdade, o ajuste do mesmo conferiu credibilidade à ação estatal e à estratégia nacional adotada, e estimulou a cooperação entre os diversos grupos - e está pautado na valorização de uma burocracia estatal competente e na inserção no arcabouço institucional da Comunidade Européia com seus incentivos e desafios.

Como coloca Bresser-Pereira (2005, p. 3), uma estratégia nacional de desenvolvimento é " sempre uma ação efetivamente concertada de uma nação; é uma instituição através da qual a nação orienta a ação dos agentes econômicos nacionais e reduz sua incerteza; é uma acordo informal e relativamente frouxo entre as classes, que não impede os conflitos internos, mas que supõe ação coletiva ou cooperação em relação aos competidores externos; é um conjunto de valores e normas que tem como critério fundamental defender o trabalho, o conhecimento e o capital nacionais, seja protegendo-os da competição internacional seja definindo políticas para torná-los mais capazes de competir. Em outras palavras, da mesma forma que a constituição é a instituição formal central de um país, uma estratégia nacional de desenvolvimento é sua instituição informal fundamental (...)". Estes elementos certamente aparecem exemplificados na experiência irlandesa, e são instrumentais para a explicação de seu sucesso.

\section{REFERÊN CIAS BIBLIOGRÁFICAS}

BRESSER-PEREIRA, LC. 2005. "Estratégia N acional de Desenvolvimento". EESP Working Paper: Www.bresserpereira.org.br.

CERRA, V e SOIKKELI, J. 2002. "H ow competitive is Irish manufacture?" I M F Working Paper, WP/02/160. 
DEPARTM EN T OF FIN AN CE. "Government of Ireland". 2006. Budgetary and E conomic Statistics. DOR N BUSCH , R. 1988. Credibility, debt and unemployment: Ireland's failed stabilization. N BER Working Paper, no 2785.

GOVERN M EN T OF IRELAN D. 2004. Economic Review and O utlook.

H ON OHAN , P. 1998. "Fiscal Adjustment and Disinflation in Ireland Setting the M acro Basis of Economic Recovery and Expansion". In Frank Barry (ed). 1999. Understanding I reland's E conomic G rowth. NY: St. M artin's Press.

LEE, JJ. 1989. I reland: 1912-1985 Politics and Society. Cambridge: Cambridge University Press.

M CALEESE, D e M CCARTHY, FD. 1989. Adjustment and External Shocks in I reland. Washington, DC: International Economics Dept., World Bank.

M cCARTHY, FD. 2001. "Social Policy and M acroeconomics: The Irish Experience". Policy Research Working Paper 2736, World Bank.

O 'CO N N ELL, P e R OTTM AN , D. 1992. "The Irish Welfare State in Comparative Perspective" . In Goldthorpe, J e Whelan, C (eds). The D evelopment of Industrial Society in I reland. London: The British Academy and Oxford University Press.

O 'D O N N ELL, R. 1998. "Ireland's Economic Transformation". Center for West European Studies, WP $\mathrm{n}$-2, University of Pittsburgh.

OECD (2001), Economic Survey of I reland, OECD Policy Brief.

O 'GRADA, C. 2001. From 'Frugal comfort ' to Ten Thousand a Year; Trade and G rowth in the Irish E conomy. Dublin: University College.

O 'GRADA, C e O'R OURKE, K. 1995. "Irish Economic Growth 1950-1988". In N .F.R Crafts e G. Toniolo (eds). Economic Growth in Europe since 1945. Cambridge: Cambridge University Press.

WAGLE, S e SH AH, P. 2003. "Ireland: Participation in M acroeconomic Policy M aking and R eform". Social D evelopment N otes. Participation and Civic Engagement Group, World Bank. 